\title{
Acrylated hyperbranched polymer photoresist for ultra-thick and low-stress high aspect ratio micropatterns
}

\author{
Lars Erik Schmidt ${ }^{1}$, Soyeon $\mathrm{Yi}^{2}$, Young-Hyun $\mathrm{Jin}^{2}$, Yves Leterrier ${ }^{1}$, \\ Young-Ho Cho ${ }^{2}$ and Jan-Anders E Månson ${ }^{1}$ \\ ${ }^{1}$ Laboratoire de Technologie des Composites et Polymères (LTC), Ecole Polytechnique Fédérale de \\ Lausanne (EPFL), Station 12, CH-1015 Lausanne, Switzerland \\ ${ }^{2}$ Digital Nanolocomotion Center, Korea Advanced Institute of Science and Technology, 373-1 \\ Guseong-dong, Yuseong-gu, Daejeon 305-701, Republic of Korea \\ E-mail: jan-anders.manson@epfl.ch
}

Received 31 October 2007, in final form 15 February 2008

Published 11 March 2008

Online at stacks.iop.org/JMM/18/045022

\begin{abstract}
Different photocurable acrylates, including two hyperbranched monomers, are compared with an epoxy negative-tone photoresist (SU-8) with respect to their suitability for the fabrication of ultra-thick polymer microstructures in a photolithographic process. To this end, a resolution pattern was used and key parameters, such as the maximum attainable thickness and aspect ratio, the minimum resolution and the processing time were determined. Compared to SU- 8 , all acrylate materials allowed the fabrication of thicker layers with a fast single layer fabrication procedure. Microstructures with thicknesses of up to $850 \mu \mathrm{m}$, an aspect ratio of up to 7.7, a 5.5-fold reduction in internal stress and a 6-fold reduction in processing time compared to SU-8 were demonstrated using an acrylated hyperbranched polyether. The specific development process of the hyperbranched polymer combined with channel design moreover enabled us to produce a high-performance valve for micro-battery devices.
\end{abstract}

\section{Introduction}

Polymer materials are well suited for the cost-effective production of microstructures, enabling cheap disposable devices to be manufactured, for example for microfluidic applications [1]. For some of these devices [2, 3], comparatively thick polymer layers in the order of a few hundred micrometers are required, such as those based on polydimethysiloxane (PDMS) and fabricated by a simple but time-consuming molding process using photoresist patterns as a master. Processes used for microstructuring polymer materials for microsystem applications include replication methods and direct techniques [4]. Replication methods involve a patterning step using the so-called master, whereas in direct techniques no such step is necessary. In the case of photolithography processes, the two materials most widely used are SU-8, an epoxy negative-tone photoresist and Novolak-type negative photoresists. Both materials are however limited in the maximum attainable thickness.
Novolak-type photoresists enable a layer thickness of up to $100 \mu \mathrm{m}$ to be reached in a single layer process and $200 \mu \mathrm{m}$ in a multilayer process with an aspect ratio of up to 10 [5-7]. Thick, high aspect ratio SU-8 structures with layer thicknesses over $200 \mu \mathrm{m}$ can only be produced in a protracted multilayer process, with fabrication times of over $1 \mathrm{~h}$ per $100 \mu \mathrm{m}$ $[8,9]$ or by using an optimized process cycle with lower baking temperatures [10]. Another time-consuming process is the development of the microstructures, although several methods were proposed to shorten this process. One method consists of stirring the development solution in order to increase diffusion through improved mixing [11] although stirring at high rates can harm microstructures. Another method, applicable if the density of the developer solution and the unreacted polymer differ, is to put the substrate upside down to facilitate the exchange of the developer solution [12]. Sonic agitation [11] was also found to increase the development rate, but it should be carried out well above the resonance frequencies of the microstructure, i.e. in the megasonic frequency range. 
(a)<smiles>C=CC(=O)OCC(COCC(COC(=O)C=C)(COC(=O)C=C)OC(=O)C=C)(COC(=O)C=C)COC(=O)C=C</smiles>

(c)

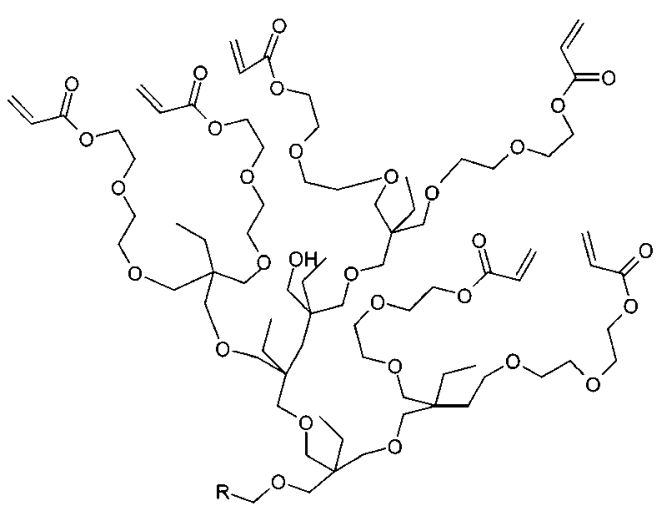

(b)<smiles>[R]COC(=O)C(C)(COC(=O)C=C)COC(=O)C(C)(CO)COC(=O)C=C</smiles>

(d)

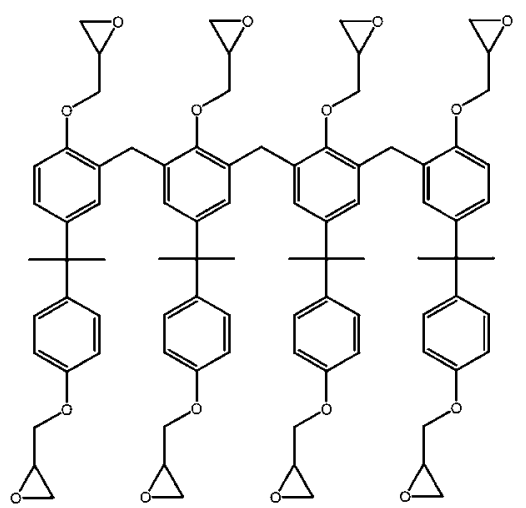

Figure 1. Structures of the acrylate monomers studied. For the hyperbranched polymers, only one sample branch is shown. $R$ denotes the core molecule, from which four branches grow out: (a) Di-Pentaerythritol Hexaacrylate (DPHA), (b) segment of acrylated Boltorn H20, (c) segment of acrylated polyether HBP and $(d)$ SU-8 monomer.

The main limiting factor of SU-8 is in fact its high level of shrinkage leading to internal stresses, typically above $25 \mathrm{MPa}$ resulting in wafer deflection and defects [8]. During fabrication of SU-8 two mechanisms contribute to shrinkage: first the evaporation of the solvent during the soft-bake step and second the chemical shrinkage during UV and thermal crosslinking in the exposure and the post-exposure or hard bake steps. Cooling down after the post-exposure bake and hard bake leads to further stresses due to a mismatch in the coefficients of thermal expansion of SU-8 and the substrates, typically $\mathrm{Si}$. A promising approach for reducing the stress was proposed in recent years for both thermosetting and photosetting polymers, based on the introduction of multifunctional hyperbranched polymers (HBPs). Such molecules are low-cost alternative to dendrimers with similar physical and rheological properties. A drastic stress reduction was reported in the case of HBP modified epoxy resins, which was attributed to an increased relaxation capacity of the epoxy network during crosslinking and a stress concentration mechanism at the epoxy/HBP interface [13, 14]. Similar results were obtained in the case of UV curable blends of acrylates and acrylated HBPs [15-18]. The benefit of such low-stress materials to produce high aspect ratio microstructures was confirmed in a recent work [19], although the development process and related dimensional accuracy were not specifically investigated.

The objective of this work was thus to evaluate the potential of highly functional acrylates based on hyperbranched architectures as resists for thick polymer microstructures with a reduced internal stress, with attention paid to dimensional accuracy and processing time.

\section{Materials and experimental methods}

\subsection{Materials}

Figure 1 depicts the structures of SU-8 2100 (Microchem, US) and of the different acrylate monomers studied. For the hyperbranched polymers (HBPs) only one sample branch is shown, since every single HBP molecule has a different structure. Di-pentaerythritol hexaacrylate (DPHA, UCB Chemicals) is an acrylate monomer with, theoretically, six functional groups but on average five functional groups. Two HBPs were also examined. The first one was based on a 16-hydroxyl functional second generation hyperbranched polyester (Boltorn ${ }^{\circledR} \mathrm{H} 20$, Perstorp AB, Sweden) giving a 13 functional polyester acrylate (called acrylated Boltron H20). The second one was based on a third generation hyperbranched polyether polyol (synthesized by Perstorp AB, Sweden) giving a 29 functional polyether acrylated (called acrylated polyether HBP).

The photoinitiator used for photocuring the acrylates was Irgacure 500 (Ciba Specialty Chemicals), a mixture of equal parts of 1-hydroxy-cyclohexyl-phenyl-ketone (CAS 947-19$3, M=204.26 \mathrm{~g} \mathrm{~mol}^{-1}$ ) and benzophenone (CAS 119-61-9, $\left.M=182.22 \mathrm{~g} \mathrm{~mol}^{-1}\right)$, at a concentration equal to $2 \mathrm{wt} \%$. It was blended with different acrylate monomers at a temperature of $85^{\circ} \mathrm{C}$ to facilitate mixing.

\subsection{Fabrication}

The mask was divided into $1 \times 2 \mathrm{~cm}^{2}$ rectangular areas containing round and rectangular features of different sizes allowing the determination of the resolution, undercut, shape 


\section{|}

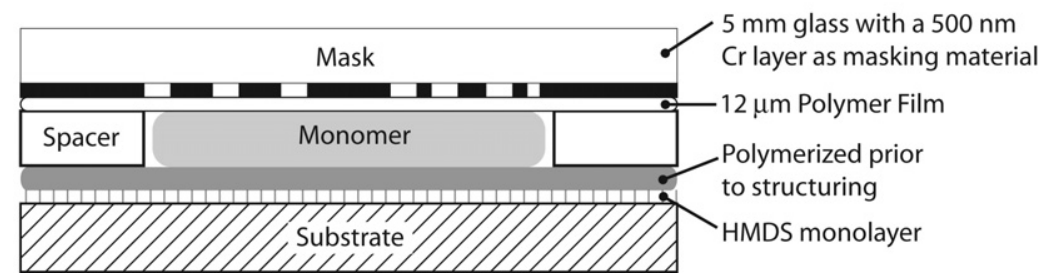

Figure 2. Photolithographic fabrication method. The collimated UV light was produced from a Hg lamp with an intensity maximum at 365 nm (Hg i-line).

fidelity and development of a given fabrication condition and material. These features included patterns of columns with square and round cross sections, channels open on the top side only and channels open on three sides.

The SU-8 reference structure was produced according to the specifications of the supplier. The maximum obtainable thickness, using a standard one-layer process was $105 \mu \mathrm{m}$. Due to the high internal stresses a $1.5 \mathrm{~mm}$ thick Si wafer was used. The fabrication included dehydration of the wafer for $15 \mathrm{~min}$ at $200^{\circ} \mathrm{C}$, spin coating of the SU-8 solution at $500 \mathrm{rpm}$ for $10 \mathrm{~s}$ and at $1000 \mathrm{rpm}$ for $30 \mathrm{~s}$. The solvent in the SU-8 was then removed by soft baking at $65^{\circ} \mathrm{C}$ for $30 \mathrm{~min}$ and at $95^{\circ} \mathrm{C}$ for $90 \mathrm{~min}$. Subsequently, the wafer was exposed to UV light for $35 \mathrm{~s}$ at an intensity of $20 \mathrm{~mW} \mathrm{~cm} \mathrm{~cm}^{-2}$ at the $365 \mathrm{~nm}$ peak ( $\mathrm{Hg}$ iline), which corresponded approximately to an UV-A intensity of $50 \mathrm{~mW} \mathrm{~cm}^{-2}$. The wafer was baked again at $65^{\circ} \mathrm{C}$ for $1 \mathrm{~min}$ and at $95^{\circ} \mathrm{C}$ for $20 \mathrm{~min}$ and finally developed in 1-methoxy-2propyl acetate for $20 \mathrm{~min}$ and rinsed with 2-propanol for $15 \mathrm{~s}$.

In the case of acrylates, which are liquid at room temperature, the following method was used: in the first step, to improve adhesion between the polymer and the glass or silicon substrate a physical vapor deposition of hexamethyl disilazane (HMDS, CAS 999-97-3) was carried out at $170^{\circ} \mathrm{C}$ for $30 \mathrm{~min}$ at ambient pressure. For further improving the adhesion, a thin layer of the acrylate (about $30 \mu \mathrm{m}$ ) was spin coated on the substrate in the second step $(1500 \mathrm{rpm}$ for $10 \mathrm{~s}$ and $3000 \mathrm{rpm}$ for $30 \mathrm{~s}$ ) and cured at room temperature during $60 \mathrm{~s}$ under an intensity equal to $20 \mathrm{~mW} \mathrm{~cm}^{-2}$ at the $365 \mathrm{~nm}$ peak. The microstructures were produced in the third step, using glass spacers to control the thickness of the liquid monomer and a $12 \mu \mathrm{m}$ thick PET film placed between the mask and monomer to protect the mask (figure 2). The polymer thickness investigated was between 150 and $1000 \mu \mathrm{m}$. After exposure, the mask and PET film and the spacer were removed carefully and the device was placed in the development solution (1-methoxy-2-propyl acetate; CAS 108-65-6). In order to improve development, the solution was stirred and the sample was put upside down into the solution (density of 1-methoxy-2-propyl acetate $0.970 \mathrm{~g} \mathrm{~cm}^{-3}$; density of the acrylate monomers $>1.1 \mathrm{~g} \mathrm{~cm}^{-3}$ ).

\subsection{Internal stress}

The in-plane internal stress of acrylate coatings was determined from the curvature of coated aluminum beams, and calculated according to the models of Stoney [20] and Inoue [21]. The substrate was a $0.3 \mathrm{~mm}$ thick aluminum strip with a length of $180 \mathrm{~mm}$ and a width of $8 \mathrm{~mm}$, which was degreased and treated with a silane compound (2-propenoic acid, 2-methyl-, 3-(trimethoxysilyl)propyl, silquest A-174, GE Silicones) in order to promote the adhesion of the acrylate coating. The acrylates were diluted in tetrahydrofurane (THF), applied on the aluminum strip and the solvent was evaporated during $2 \mathrm{~h}$ at $80{ }^{\circ} \mathrm{C}$. The samples were cured in a nitrogen atmosphere. Their Young's modulus was measured on rectangular specimens $\left(20 \times 4 \times 0.15 \mathrm{~mm}^{3}\right)$ using a miniature tensile tester (Minimat, Rheometric scientific) equipped with video extensometry, with a strain resolution better than $10^{-3}$, and was found to be equal to $3.2 \mathrm{GPa}, 3.9 \mathrm{GPa}$ and $1.1 \mathrm{GPa}$ for DPHA, acrylated Boltorn H20 and acrylated polyether HBP, respectively.

The in-plane internal stress of SU-8 coatings was calculated using the same models as for the acrylates, based on curvature measurements performed by Lorenz et al of SU8-coated silicon wafers after post-exposure baking [8]. The wafer was $380 \mu \mathrm{m}$ thick and the deflection was measured between two $40 \mathrm{~mm}$ distant supports. The SU-8 coating thickness varied from 6.75 to $200 \mu \mathrm{m}$. For SU-8 the modulus was set at $3 \mathrm{GPa}[10]$ and the Poisson's ratio at 0.33 [11] and for the Si wafer the modulus was assumed to be $170 \mathrm{GPa}$ and Poisson's ratio 0.26 [12].

\section{Results and discussion}

\subsection{Development}

Figure 3 represents the influence of the process parameters (exposure and development) and channel width on the development progress of SU-8 and acrylated polyether HBP. The minimum channel width required for full development was slightly larger than $50 \mu \mathrm{m}$ for SU-8, and larger than $75 \mu \mathrm{m}$ for the HBP, depending on the exposure time. In the case of the acrylated HBP, it is also evident that neither increasing the development time by a factor of 11 nor using ultrasonic agitation improved the development significantly. Reducing the exposure time from $15 \mathrm{~s}$ to $10 \mathrm{~s}$ did not change the development progress for small channels, but it did change the minimum channel width for entirely developed channels from 100 to $76 \mu \mathrm{m}$. The reason for these results is that acrylates react in a chain-wise manner, so that gelation happens at low 


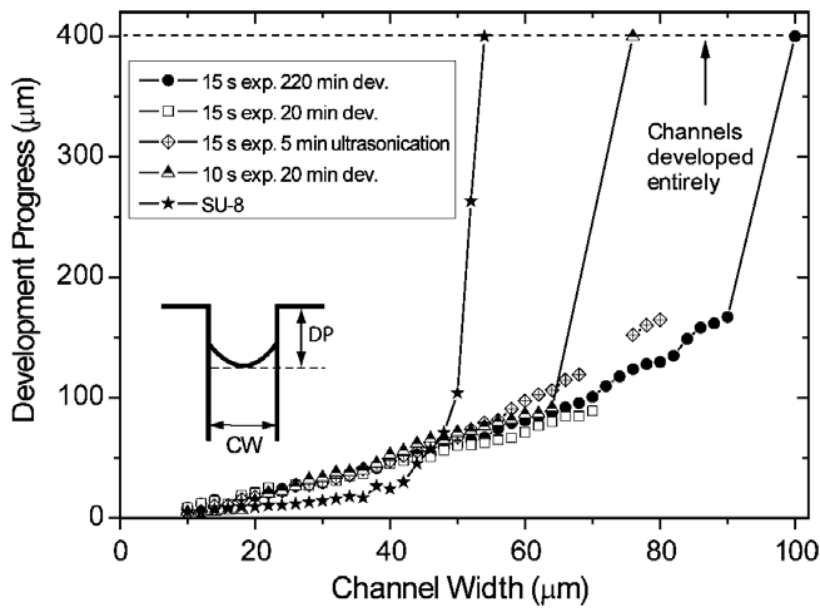

Figure 3. Influence of the development condition on the development progress DP (see the inlet) for an acrylated polyether HBP microstructure, with varying exposure times (10 $\mathrm{s}$ and $15 \mathrm{~s}$ ) and development conditions (time and agitation). The development progress is compared to a reference structure fabricated from SU-8.

conversions. Part of the UV light is scattered underneath the mask and rapidly converts the unexposed polymer present in the channel into a gel, which is no longer soluble in the developer. The adhesion between the gel and the cured polymer (of which there was also a thin layer on the substrate) was weak, so that the gel was partly removed during the development process.

Figure 4(a) shows a top view of a $80 \mu \mathrm{m}$ wide channel, partly filled with the acrylated polyether HBP. The depth of the partially developed channel was constant and the development progress was well defined. A microtip was used to scratch the polymer in the channel. It was found that the residue was not a liquid monomer remaining due to insufficient development but a soft gel. These results confirmed that development of acrylates was controlled by scattering, diffraction and refraction of UV light that led to gelation in the unexposed parts of the structure. This phenomenon practically limits the minimum channel width that can be produced using the acrylated HBP.

In contrast, in the case of SU-8, the development was not limited by light scattering, but rather by the diffusioncontrolled development process.

Figure 4(b) shows a partly developed, $25 \mu \mathrm{m}$ wide channel in SU-8, with continuously decreasing depth from top to bottom. This finding can be explained by the step-wise reaction mechanism of SU-8, with gelation at high conversion. The implication of these differences between the acrylates and the SU-8 epoxy in terms of dimensional accuracy is discussed in the following.

\subsection{Internal stress and defects}

The internal stress of SU-8 and acrylate coatings is listed in table 1. For the thinner SU-8 coatings, a stress larger than $25 \mathrm{MPa}$ was found. Compared to SU-8, all acrylate polymers had a substantially lower internal stress, from $2.4 \mathrm{MPa}$ for
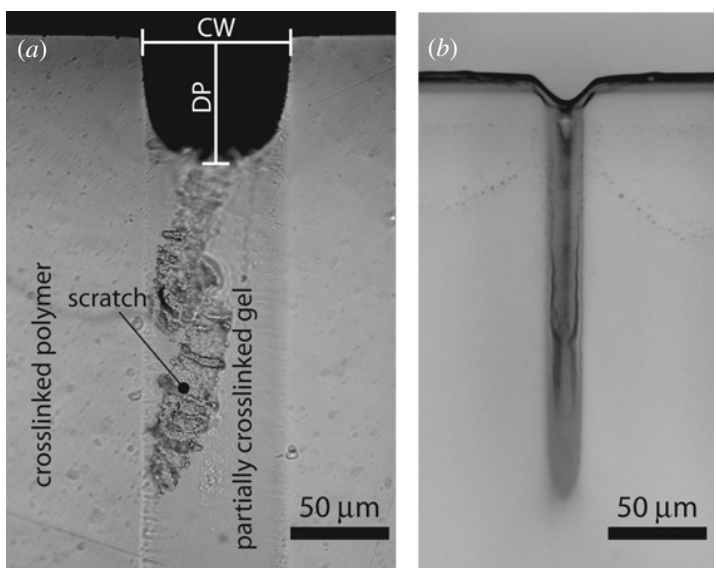

Figure 4. Microchannel fabricated $(a)$ from acrylated polyether HBP (75 $\mu \mathrm{m}$ wide) and $(b)$ from SU-8.

Table 1. In-plane internal stress in polymer coatings calculated using the Stoney and the Inoue model. See the text for details.

\begin{tabular}{llll}
\hline Material & $\begin{array}{l}\text { Coating } \\
\text { thickness }(\mu \mathrm{m})\end{array}$ & $\begin{array}{l}\text { Stress } \\
(\text { Stoney, MPa) }\end{array}$ & $\begin{array}{l}\text { Stress } \\
\text { (Inoue, MPa) }\end{array}$ \\
\hline SU-8 & 6.75 & 29.1 & 27.8 \\
SU-8 & 19 & 26.2 & 25.0 \\
SU-8 & 200 & 19.6 & 13.3 \\
Acrylated & 280 & 2.4 & 5.1 \\
$\quad \begin{array}{l}\text { polyether HBP } \\
\text { Acrylated }\end{array}$ & 220 & 4.5 & 3.6 \\
$\quad$ Boltorn H20 & & 6.7 & 1.4 \\
\begin{tabular}{l} 
DPHA \\
\hline
\end{tabular}
\end{tabular}

the polyether $\mathrm{HBP}$ over 4.5 MPa for the acrylated Boltorn $\mathrm{H} 20$ to $6.7 \mathrm{MPa}$ for DPHA [17]. Excessive internal stresses may relax through cracking, as shown in figure 5 in the case of DPHA and SU-8 structures. Crack formation is a wellknown phenomenon for SU-8 [22]. It was overcome by a so-called hard-baking step after development [23], in spite of an increased internal stress [8]. This contradictory effect may result from the thermal expansion of SU-8 during the hardbaking step and cure of residual epoxy groups leading to crack closure. In the acrylated polyether HPB and the acrylated Boltorn $\mathrm{H} 20$ no cracks could be detected, which should prove beneficial to produce microstructures with high-dimensional accuracy, and to which we turn our attention.

\subsection{Dimensional accuracy}

The dimensional accuracy of model microstructures was defined with four parameters, namely the fidelity, the distortion, the undercut and the aspect ratio, summarized in table 2, and detailed as follows.

The fidelity and distortion parameters were determined using L-shaped structures (figure 6). The fidelity was defined as the ratio of the actual length divided by the target length (400 $\mu \mathrm{m}$ ) and the distortion was defined as the deviation angle between the actual angle of the corner of the structure and the reference angle $\left(90^{\circ}\right)$. The fidelity is controlled by polymerization shrinkage and solvent attack during the 

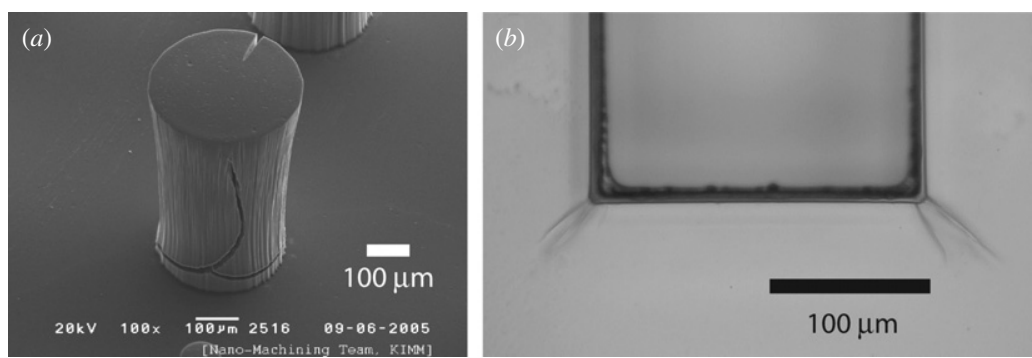

Figure 5. Defects due to internal stress $(a)$ in a $400 \mu \mathrm{m}$ tall micropillar produced from DPHA and $(b)$ at the edges of open cavities fabricated from SU-8.
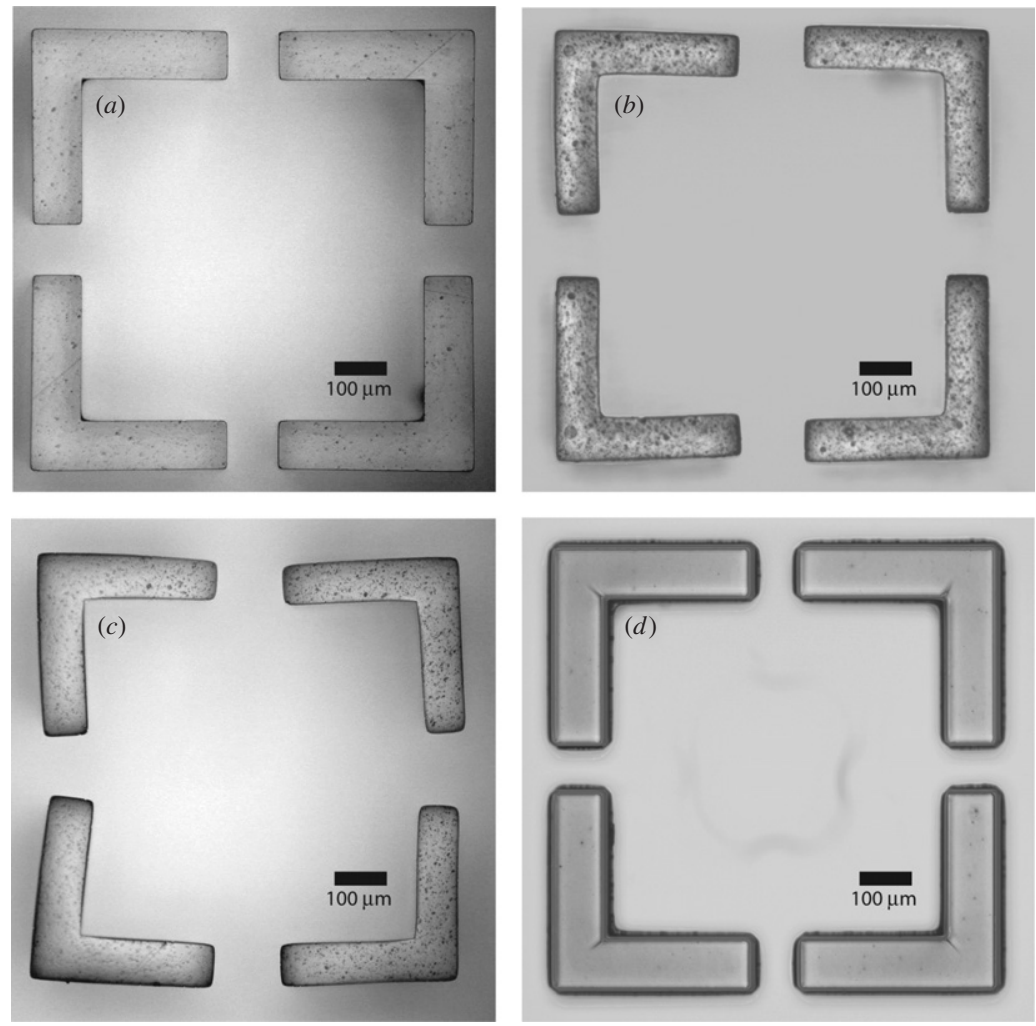

Figure 6. Top view of a (a) $420 \mu \mathrm{m}$ high structure fabricated from the polyether HBP and (b) $500 \mu \mathrm{m}$ acrylated Boltorn $\mathrm{H} 20$ (c) $400 \mu \mathrm{m}$ DPHA and $(d) 105 \mu \mathrm{m}$ SU-8 2100. Due to internal stresses the DPHA and the acrylated Boltorn H20 is deformed, whereas the polyether HBP has good shape accuracy. In SU-8 the internal stress did not cause deformation, but cracks in corners and delamination.

Table 2. Overview of the performance of different photoresists. The aspect ratio was determined as the height of the smallest square column divided by its width. The internal stress for the acrylates was taken from [1]. The angle deviation was determined as the deviation of the $90^{\circ}$ angle of the structure with an L cross section. The length accuracy was determined by comparing the actual and target length of a feature with a rectangular cross section.

\begin{tabular}{lllllllrr}
\hline Resist & $\begin{array}{l}\text { Layer } \\
\text { thickness }(\mu \mathrm{m})\end{array}$ & $\begin{array}{l}\text { Aspect } \\
\text { ratio }\end{array}$ & $\begin{array}{l}\text { Smallest development } \\
\text { channel }(\mu \mathrm{m})\end{array}$ & $\begin{array}{l}\text { Angle } \\
\text { deviation }\left({ }^{\circ}\right)\end{array}$ & $\begin{array}{l}\text { Length } \\
\text { accuracy }\end{array}$ & $\begin{array}{l}\text { Undercut } \\
\text { angle }\left(^{\circ}\right)\end{array}$ & $\begin{array}{l}\text { Internal } \\
\text { stress }(\mathrm{MPa})\end{array}$ & $\begin{array}{l}\text { Processing } \\
\text { time }(\mathrm{min})\end{array}$ \\
\hline Polyether HBP & 420 & 7.7 & 145 & 0.7 & $95.6 \%$ & 3.41 & 2.4 & 30 \\
Polyether HBP & 850 & 6.0 & 190 & & & & 2.4 & 30 \\
DPHA & 400 & 3.1 & 85 & 4.8 & $92.9 \%$ & 2.65 & 6.7 & 30 \\
Acrylated Boltorn H20 & 500 & 3.3 & 70 & 2.2 & $94.9 \%$ & 1.04 & 4.5 & 30 \\
SU-8 & 105 & 10.5 & 65 & 0.58 & $98.6 \%$ & 2.15 & $>19.6$ & 240 \\
\hline
\end{tabular}

development step, and was found to be equal to 0.986 for the SU-8, close to 0.95 for the acrylated HBPs, and equal to 0.929 for DPHA. The structure produced from the acrylated polyether HBP showed the lowest distortion, and that from DPHA the highest due to the higher internal stresses. For SU-8 a distortion of $1.0^{\circ}$ was measured, indicating that SU-8 


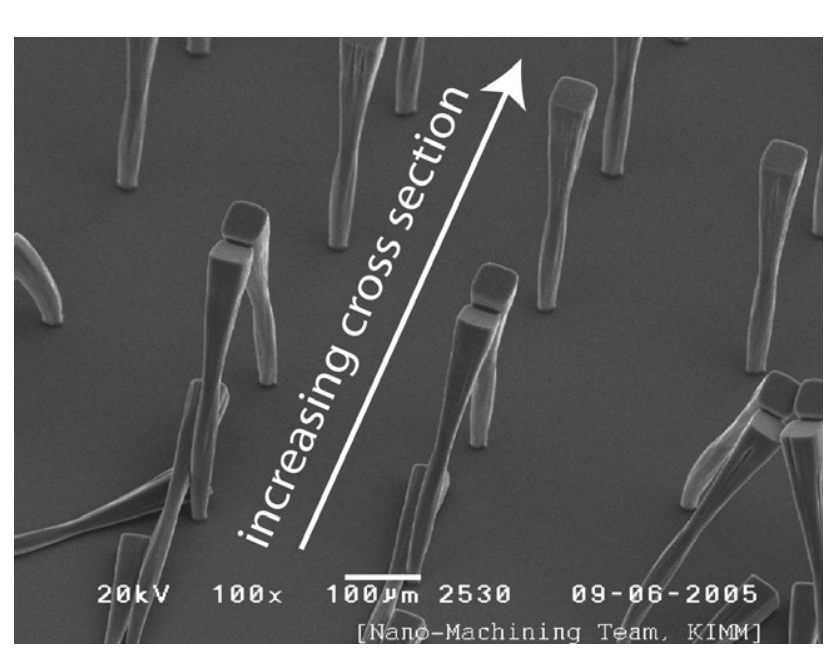

Figure 7. Micropillar array produced from acrylated polyether HBP with an increasing pillar cross section ( $2 \mu \mathrm{m}$ steps $)$ and a height of $420 \mu \mathrm{m}$.

does not release any internal stress through dimensional change but through cracking.

The undercut was defined as the angle between the edge of a column and the normal to the wafer surface. The lowest value was determined for the acrylated Boltorn $\mathrm{H} 20$ and the highest for the acrylated polyether HBP. This phenomenon, which limits the dimensional accuracy of polymer microstructures based on negative-type photoresists, results from oxygen inhibition mechanisms coupled to oxygen diffusion from unexposed areas [24]. It is therefore not directly linked to the level of internal stresses responsible for the observed distortions.

The aspect ratio was defined as the height to width ratio of a square column and evaluated with a micropillar array with rows of columns of increasing width ( $2 \mu \mathrm{m}$ for every row as shown in figure 7). The first row of straight, non-deformed columns was taken to calculate the aspect ratio. Among the three acrylates the polyether HBP showed the highest aspect ratio. For a layer thickness of $420 \mu \mathrm{m}$ it was 7.7 and for a layer thickness of $850 \mu \mathrm{m}$ it was 6.0. The acrylated Boltorn H20 had a maximum aspect ratio of 3.3 (for a $500 \mu \mathrm{m}$ thick layer), which was similar to that of DPHA (3.1 for a $400 \mu \mathrm{m}$ thick layer). For SU-8 aspect ratios up to 10.5 could be obtained, although with a thickness limited to $105 \mu \mathrm{m}$ and at the expense of increased processing time. Elsewhere aspect ratios up to 18 were found [8].

Figure 8 compares arrays of round and square columns fabricated from the acrylated polyether HBP and SU-8. While the array of acrylated polyether HBP shows clear circular and square shapes, the array of $\mathrm{SU}-8$ has a rounded edge of the square columns, though it has a lower height. These results confirm that low-stress acrylated HBPs are promising materials for producing ultra-thick, high aspect ratio polymer microstructures.

\subsection{Micro-battery device}

A micro-battery channel structure having a series of unit cells [2] was produced using the proposed fabrication process with
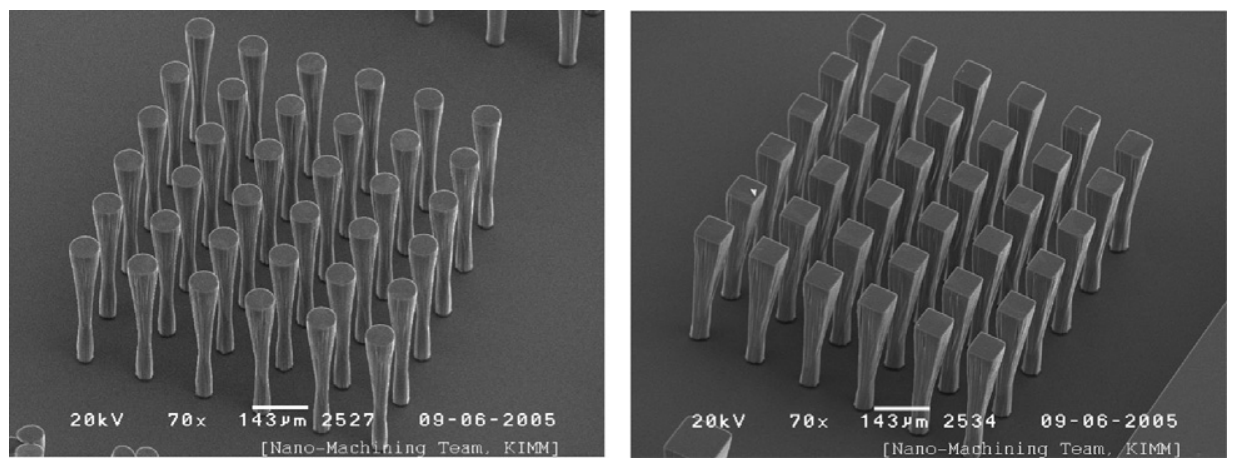

(a)
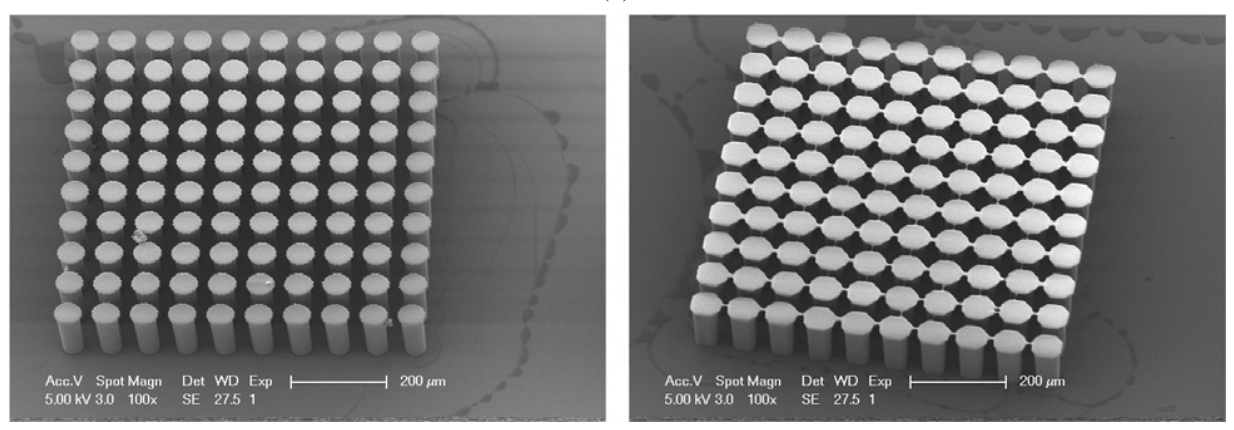

(b)

Figure 8. Array of round and square columns fabricated in a photolithographic process: (a) from acrylated polyether HBP; (b) from SU-8. 

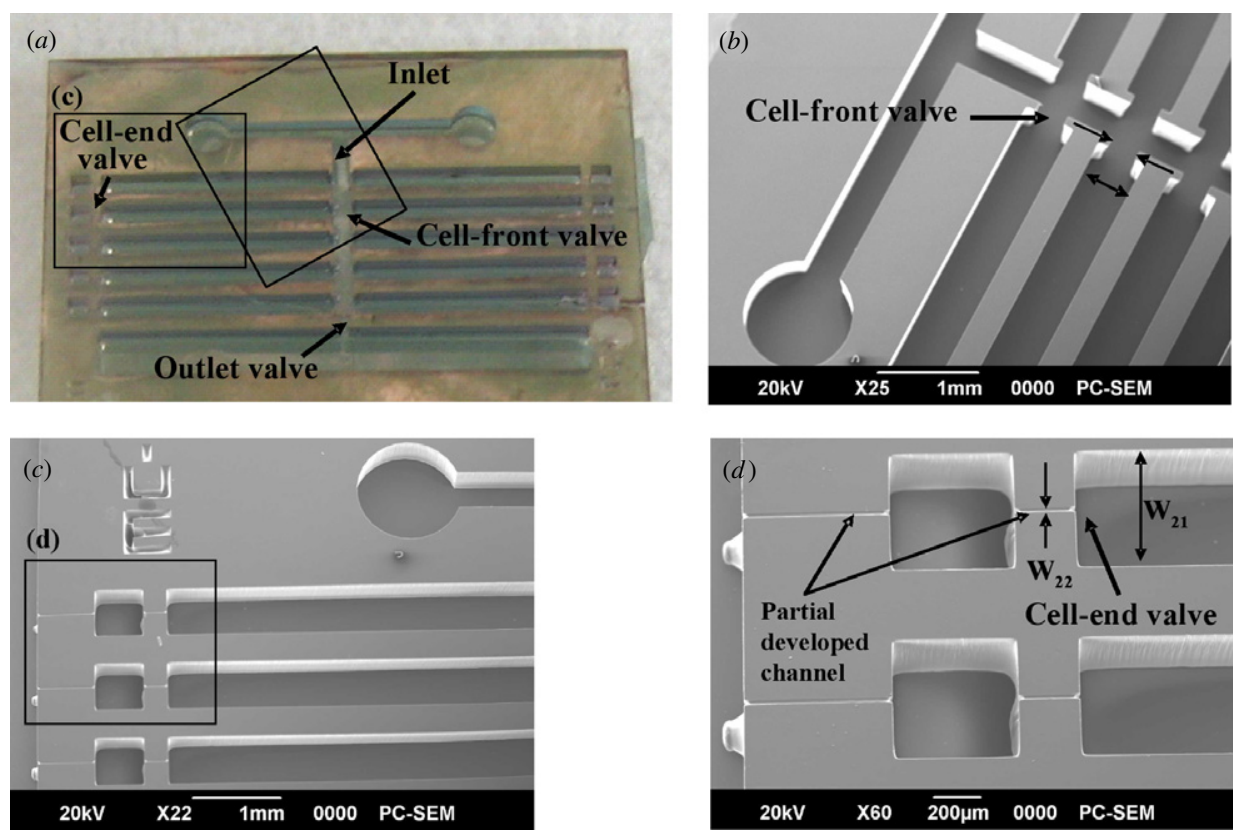

Figure 9. Fabricated micro-battery: (a) micro-battery having a series of unit cells; $(b)$ enlarged view of section $\mathrm{b}$ in $(a)$ around the cell-front valve; $(c)$ enlarged view of the section $\mathrm{c}$ in $(a)$ around the cell-end valve; $(d)$ enlarged view of the cell-end valve of section $\mathrm{d}$ in $(c)$.

Table 3. Designed and fabricated dimensions of the micro-battery in figure 9 .

\begin{tabular}{llcc}
\hline & & $\begin{array}{l}\text { Designed } \\
\text { dimension }(\mu \mathrm{m})\end{array}$ & $\begin{array}{l}\text { Fabricated } \\
\text { dimension }(\mu \mathrm{m})\end{array}$ \\
\hline Cell-front valve & $W_{11}$ & 500 & $512 \pm 3.1$ \\
& $W_{12}$ & 300 & $309 \pm 2.5$ \\
Cell-end valve & $W_{21}$ & 500 & $512 \pm 3.1$ \\
& $W_{22}$ & 20 & $18.0 \pm 1.2$ \\
Channel depth & $T$ & 1000 & $1000 \pm 25$ \\
\hline
\end{tabular}

the acrylated polyether HBP. The chip size was $2.22 \mathrm{~cm} \times$ $1.45 \mathrm{~cm}$ and consisted of two inlet ports, one outlet chamber and 10, 20 and 40 unit cells including the channel and valve. The chip structure is detailed in figure 9 with enlarged views of the cell-front valve and cell-end valve. Table 3 gives the values of the designed and measured channel and valve dimensions. It is evident that the width of the fabricated channels matches the designed dimensions within less than $3 \%$. The fidelity and distortion (defined in section 3.3) of a $500 \mu \mathrm{m}$ wide channel are equal to 0.976 and $1.1^{\circ}$, values that are very close to the values obtained for the model microstructures.

The channel with widths of $500 \mu \mathrm{m}\left(\boldsymbol{W}_{11}, \boldsymbol{W}_{\mathbf{2 1}}\right)$ and $300 \mu \mathrm{m}\left(\boldsymbol{W}_{\mathbf{1 2}}\right)$ were fully developed. In contrast, the cellend valve channel having a width of $20 \mu \mathrm{m}\left(\boldsymbol{W}_{\mathbf{2 2}}\right)$ was only partly developed with a depth of $4.04 \pm 1.59 \mu \mathrm{m}$. These results are consistent with the development data depicted in figure 3 , showing that the minimum channel width for full development is equal to $76 \mu \mathrm{m}$. Thanks to this width-dependent development specific to the HBP material, a valve with an extremely high cross-sectional ratio could be achieved by a one-step photolithographic process. This unique development property moreover enabled us to construct 3D funnel shape channels. The knowledge of development behavior (figure 3) combined with channel design enables accurate valve performance using a cost-effective process method.

\section{Conclusions}

Novel materials were proposed as negative tone resists for photolithography of ultra-thick layers. The materials included a range of acrylated hyperbranched macromolecules with a low level of process-induced internal stresses. These materials were compared to the widely used negative tone photoresist SU-8. It was found that the internal stress is the key limiting factor for producing thick micropatterns.

In the case of acrylates, light scattering was found to limit the development of narrow channels, whereas in the case of SU-8 the development was diffusion controlled.

The acrylated polyether HBP showed best performance with a high shape fidelity. Layer thicknesses up to $850 \mu \mathrm{m}$ and aspect ratios up to 7.7 could be produced with this polymer in a facile single layer process. These findings suggest that future development should target on liquid, solvent-free photoresists, polymerizing entirely during UV exposure.

\section{Acknowledgments}

Financial support from the Swiss National Science Foundation (SNF project \# 2100.063675.00) and from the KoreaSwitzerland Joint Research Program of the Korea Ministry of Science and Technology (MOST) under the project title of 'NanoBioFluidic Device and Characterization,' is gratefully acknowledged. Furthermore the authors would like to thank Professor Young Ho Seo at Kangwan National University for his help in electron microscopy, David James from Perstorp 
Specialty Chemicals, Alain Lejeune from GE Silicones and Dr André Fuchs from Ciba Specialty Chemicals for technical advice and supply of materials.

\section{References}

[1] Becker H and Locascio L E 2002 Polymer microfluidic devices Talanta 56 267-87

[2] Kim M C, Chang S H and Cho Y-H 2006 High-voltage liquid-electrolyte microbatteries using a series of unit cells isolated by surface tension effect The 6th Int. Workshop on Micro and Nanotechnology for Power Generation and Energy Conversion Applications: PowerMEMS 2006 (Berkley, USA)

[3] Suk S D, Chang S H and Cho Y-H 2005 Fabrication, and characterization of electrical and fluidic interconnections for a multi-chip microelectrofluidic bench 18th IEEE Int. Conf. on Micro Electro Mechanical Systmes: MEMS 2005 (Miami, USA)

[4] Becker H and Gärtner C 2000 Polymer microfabrication methods for microfluidic analytical applications Electrophoresis 21 12-26

[5] Löchel B et al 1995 Magnetically driven microstructures fabricated with multilayer electroplating Sensors Actuators A 46-47 98-103

[6] Roth S et al 1999 High aspect ratio UV photolithography for electroplated structures J. Micromech. Microeng. 9 105-8

[7] Conédéra V, Goff B L and Fabre N 1999 Potentialities of a new positive photoresist for the realization of thick moulds J. Micromech. Microeng. 9 173-5

[8] Lorenz H et al 1998 High-aspect-ratio, ultrathick, negative-tone near-UV photoresist and its applications for MEMS Sensors Actuators A 64 33-9

[9] Williams J D and Wang W 2004 Study on the postbaking process and the effects on UV lithography of high aspect ratio SU-8 microstructures J. Microlithogr. Microfabr. Microsyst. 3 563-8

[10] Kubenz M et al 2003 Challenges of processing thick and ultra-thick photoresist films Advances in Resist Technology and Processing XX: Proc. SPIE 5039 1272-80
[11] Williams J D and Wang W 2004 Using megasonic development of SU-8 to yield ultra-high aspect ratio microstructures with UV lithography Microsyst. Technol. 10 694-8

[12] Cheng C-M and Chen R-H 2001 Development behaviours and microstructure quality of downward-development in deep x-ray lithography J. Micromech. Microeng. 11 692-6

[13] Mezzenga R, Boogh L and Månson J-A E 2001 A review of dendritic hyperbranched polymer as modifiers in epoxy composites Comp. Sci. Technol. 61 787-95

[14] Eom Y et al 2002 Internal stress control in epoxy resins and their composites by material and process tailoring Polym. Comp. 23 1044-56

[15] Klee J E et al 2001 Hyperbranched polyesters and their application in dental composites: monomers for low shrinking composites Polym. Adv. Technol. 12 346-54

[16] Kou H-G, Asif A and Shi W-F 2003 Hyperbranched acrylated aromatic polyester used as a modifier in UV-curable epoxy acrylate resins Chin. J. Chem. 21 91-5

[17] Schmidt L E et al 2005 Structural and residual stress analysis of UV curable hyperbranched acrylates RadTech Europe (Barcelona)

[18] Schmidt L E et al 2007 Time-intensity-transformation and internal stress in UV-curable hyperbranched acrylates Rheol. Acta 46 693-701

[19] Jin Y-H et al 2007 A fast low-temperature micromolding process for hydrophilic microfluidic devices using UV-curable acrylated hyperbranched polymers J. Micromech. Microeng. 17 1147-53

[20] Stoney G G 1909 The tension of metallic films deposited by electrolysis Proc. R. Soc. A 82 172-5

[21] Inoue Y and Kobatake Y 1958 Mechanics of adhesive joints: part III. Evaluation of residual stress Appl. Sci. Res. A 7 314-24

[22] Tseng F-G and Yu C-S 2002 High aspect ratio ultrathick micro-stencil by JSR THB-430N negative UV photoresist Sensors Actuators A 97-98 764-70

[23] Rabarot M et al 2003 Thick SU-8 photolithography for BioMEMS Micromachining and Microfabrication Process Technology VIII: Proc. SPIE $4979382-93$

[24] Smith D K 1968 A mathematical model of photometric oxygen consumption in photopolymer Photogr. Sci. Eng. 12 263-6 